\title{
Neither teacher-centred nor student-centred: threshold concepts and research partnerships
}

\section{Glynis Cousin}

University of Wolverhampton, UK

\begin{abstract}
In this paper I argue that pedagogic research organised around the investigation of threshold concepts offers a fresh way of thinking about research collaboration with students, academics and educational developers. I will first introduce the basic ideas about threshold concepts, briefly contrasting it with the phenomenographic tradition. I suggest that threshold concept inquiry effects a turn from this tradition by: a) encouraging partnerships with educationalists, students and subject specialists; and b) by a focus on the difficulty of the subject rather than on general education theory.
\end{abstract}

Keywords: threshold concepts; partnerships with students; partnerships with subject specialists; research methods.

\section{Threshold concepts}

The idea of threshold concepts came from a UK national research project into the possible characteristics of strong teaching and learning environments in the disciplines for undergraduate education (Enhancing Teaching-Learning Environments in Undergraduate Courses 2001-2004 (www.etl.tla.ed.ac.uk). From involvement in the economics strand of this research, Erik Meyer and Ray Land (2006) argued that certain concepts were held by economists to be central to the mastery of their subject. Further investigation in other subjects (Land et al., 2008) showed this to be true of any subject. Threshold concepts could be described as 'threshold' ones because they have the following characteristics: 


\section{Transformative}

1. Grasping a threshold concept is transformative because it involves an ontological as well as a conceptual shift in the learner. We are what we know. New understandings are assimilated into our biography, becoming part of who we are, how we see and how we feel. An illustration would be a shift from a student of French to a French speaker. Or a student of architecture to someone who thinks like an architect.

\section{Irreversible}

2. A threshold concept is often irreversible; once understood the learner is unlikely to forget it (this does not exclude revision or rejection of the concept once understood). One of the difficulties teachers have is that of retracing the journey back to their own days of 'innocence', when understandings of threshold concepts eluded them in the early stages of their own learning. Their own understandings have become so internalised that it is hard for them to sympathise with students who are having difficulties. This is why talking to them is so important.

\section{Integrative}

3. Another characteristic of a threshold concept is that it is integrative in that it exposes the hidden interrelatedness of phenomenon. Mastery of a threshold concept often allows the learner to make connections that were hitherto hidden from their view. Things start to click into place.

\section{Bounded}

4. A threshold concept is likely to be bounded in that 'any conceptual space will have terminal frontiers, bordering with thresholds into new conceptual areas' (Meyer and Land, 2003: 6). The more interdisciplinary a subject, the more complex this will be.

\section{Troublesome}

5. Finally, a threshold concept is likely to involve forms of 'troublesome knowledge'; David Perkins (2006: 7) describes such knowledge as 'that which appears counter-intuitive, alien or seemingly incoherent'. Troublesome knowledge or 'stuckness' can be more fully understood through the notion of liminality as I next discuss, but first I should stress that 
threshold concepts are likely to be contested in any discipline and should be regarded as providing provisional stability for teaching, learning and assessment purposes.

\section{Liminality}

Learning, argue Meyer and Land (2003), involves the occupation of a liminal space during the process of mastery of a threshold concept. This space is similar to the one occupied by adolescents who are not yet adults, not quite children. It is an unstable space in which the learner may oscillate between old and emergent understandings, just as adolescents often move between adult - like and child - like responses to their transitional status. Once a learner enters this liminal space, she is engaged with the project of mastery. Threshold concept research is sited in this space, establishing a dialogue with the students about their struggles to comprehend. Here are illustrative interview extracts from Orsini-Jones' (2006) research with students of linguistics:

First student: I understood it in class, it was when we went away and I just seemed to have completely forgotten everything that we did on it, and I think that was when I struggled because when we were sat in here, we'd obviously got help if we had questions but..... when it came to applying it....I understood the lectures and everything that we did on it but couldn't actually apply it, I think that was the difficulty.

Q. Did you feel the same as student 1?

Second student: Yeah. I felt lost.

Q. In lecture times as well?

Second student: You know, I understood the concept for about lets say 10 seconds, yes yes, I got that and then suddenly, no no, I didn't get that, you know, suddenly, like this.

Note the oscillation of understanding that perfectly captures what Meyer and Land mean by a state of liminality. Now he has got it, now he hasn't. Arguably most learning involves 
this recursive process. Importantly, this is not simply a cognitive movement because it involves a strong emotional dimension concerning the student's identification with both the subject and his perceived capabilities. The following teacher expresses this well in reflecting on her students' grasp of cultural studies (Cousin, 2006:135):

Some students take to it and it changes their lives and their way of thinking and they get incredibly engaged....that's a minority...there's a bunch in the middle that work away at it and eventually get it by the third year but are in a state of high anxiety in the first year....some acquire it on the way and this becomes an important transition in their whole sense of self but there are a whole bunch of students, middle of the road, for whom they are going through the motions and are finding a utilitarian route through it.

Common ways in which students try to overcome their state of liminality is through quasi plagiarism, plagiarism or mimicry. Some just give up and leave university altogether. Involving them in a dialogue about their difficulties, as Orsini-Jones (2006) discovered, dramatically reduces these possibilities, particularly if the teacher gives them full permission to flounder, fail and forget. Here are some more examples from students (Lucas and Mladenovic, 2008: 157), this time of accounting:

I think I can see a bit more of the theoretical thing behind it..... w was probably one of the persons who wrote - it's just writing down numbers, but now I see that there's probably a bit more to it.

I didn't realise it was so central to the business world...I didn't realise it was such a big issue.

Because I thought that you had to be a mathematical genius to do accounting, and now I know it's different.

Note how the students are clearly problematising their mastery, exposing earlier preconceptions (troublesome knowledge) of the subject which were getting in the way of mastery. Here are some final examples, this time students of economics (Reimann and 
Jackson, 2006: 128-129) trying to make sense of the concept of elasticity. Each of these students point to the transformational character of learning, the importance of 'getting it':

Well, from not knowing what it is to knowing what it is, that is the big step one. So that can be knowing how to apply the concepts that we use.

There are some things you learn, you suddenly think, wow, suddenly everything seems different...you now see the world quite differently.

These quotes come from research which explores the difficulty of the subject with students and teachers; they constitute something of a turn away from the phenomenographic approach which has characterised much higher education inquiry. While this has been a valuable approach in so many ways, arguably it has been responsible for de-centring the academic teacher in its emphasis on student experience research. In particular the notion of student-centredness deriving from this research has not always gone down well with academics.

\section{Killing off the teacher?}

Most educational developers and researchers would accept that they have experienced anything ranging from indifference to hostility from academics who are suspicious of the 'student-centred' changes they are asked to make. Many educational developers defensively package this suspicion as learner resistance and ignorance, seeing their challenge to be that of leading academics to the true path of student-centred teaching and learning. How many of us have paused to wonder whether academics have a point in their resistance?

Perhaps an unintended outcome of the student-centred tradition has been what one writer describes as 'the mortification of the teacherly self' (McShane, 2006). This Goffmanesque melodramatic notion aids an exploration into how educational developers have often viewed their task as that of dismantling and outlawing 'teacher-centredness' in favour of 'student-centredness'. In pursuing this task, educational developers have not always trod carefully on territory which is held to be sacred by academics. One example is in the disdain many educationalists have for lectures as outdated and unsatisfactory modes of Journal of Learning Development in Higher Education, Issue 2: February 2010 
knowledge dissemination. I sometimes detect an irritation from academics about this and the associated tendency of educationalists to privilege technique over theatre. For instance, educationalist advice to abandon lectures undermines an understanding of the lecture's symbolic, ritual content. While traditional lectures may not be effective in linear, aligned ways, it debases their purpose to worry about this because they have a larger role.

Arguably, lectures perform identity work for both teachers and students, enabling each to feel part of the university and of the subject community. Moreover, the lecture theatre is a sacred place in the sense that it delineates a space where academics hope to exercise their freedom, where radical, interesting, contentious ideas are tested and voiced from behind a lectern. In making these points I am not suggesting that lecturing cannot be improved or sometimes replaced; nor am I suggesting that we revert to teachercentredness to tip the scales in the opposite direction. I think it is the very opposition of student-centred and teacher-centred which has exhausted its usefulness. Most binaries should be treated with caution and this is no exception. I think we need a restoration of dignity for academic teachers by placing them alongside students and educational researchers rather than above or below them. The symbolic erasure of teacher expertise in education discourse is not confined to the discourse on student-centredness; it is also present in our expectations that they become amateur educationalists.

\section{Ascending mount Kolb}

As anyone involved in accredited teacher development courses knows, getting academics to underpin their reflections on their practice using educational theory is always an uphill struggle, with most stopping for a permanent rest at mount Kolb. This is understandable because subject specialists who are not social scientists are being asked to become informed amateurs in another discipline. Threshold concept research offers a way out of this problem because it requires an emphasis on subject expertise, both for students and teachers (albeit at different levels) rather than on education. This is another point of departure from phenomenographic research. In Osmond et al's (2006: 12) research, they note the enthusiasm of teachers to discuss threshold concepts: 
Using threshold concepts as a framework has enabled the research team to open up a dialogue with the staff in a discipline that appears, in the main, to be relatively under-theorised. This usefulness of the dialogue was evidenced during the wholestaff meeting and individual interviews by the enthusiasm of the staff to participate.

It has certainly been my experience that getting academics to think about what is critical to learn in their subject is easier than getting them to think about learning outcomes. I am not suggesting that phenomenographic research never involved subject specialists. However, there are some important differences between the research framework for phenomenography and that of threshold concepts research (which does not have a settled methodological framework). Phenomenography explores student experiences for the discovery of variation in learners' reported ways of experiencing phenomenon. Phenomenographic research is on the students so that once extracted from them (often through interviews or surveys), the student experience data becomes the researcher's text to analyse, heightening the risk of the students' experience being represented through the researchers' experience of the students' experience. In so far as all research findings are the product of interpretation of some kind, I would not want to claim that threshold concept research escapes this problem entirely (indeed some threshold concept research draws heavily on this tradition) but there is an emergent trend that is apace with contemporary concerns about this kind of interpretive predicament. Whereas the convention in universities is to ask students to evaluate the quality of their teaching and learning, how they have experienced assessment, feedback, etc., the thrust of threshold concept research is to share an inquiry into the difficulty of their subject with the academics and the students. It is student-focussed but not student-centred in ways that remove the academic from the stage.

\section{Conclusion}

To conclude, I have argued that the search for threshold concepts has the potential to open up discussions among subject specialists, students and educational researchers, creating forms of transactional curriculum inquiry between these three parties. Further, I have argued that threshold concept research does not require the academic to learn another discipline; on the contrary, it requires that she goes more deeply into her own for 
the purposes of formulating the best ways of teaching and learning it. By staging the exploration at the site of the subject and of its difficulties, threshold concept research promises to establish partnership research between educational developers, students and subject specialists.

\section{References}

Cousin, G. (2006) 'Threshold concepts, troublesome knowledge and emotional capital: an exploration into learning about others', in Meyer, J.H.F. and Land, R. (eds.) Overcoming barriers to student understanding: threshold concepts and troublesome knowledge. Abingdon: Routledge.

Land, R., Meyer, J.H.F. and Smith, J. (eds.) (2008) Threshold concepts within the disciplines. Rotterdam: Sense Publications.

Lucas, P. and Mladenovic, R. (2008) 'Developing 'new world views': threshold concepts in introductory accounting', in Land, R., Meyer, J.H.F. and Smith, J. (eds.) Threshold concepts within the disciplines. London: RoutledgeFalmer.

McShane, K. (2006) Technologies transforming academics: academic identity and online teaching. Unpublished PhD thesis. University of Technology Sydney.

Meyer, J.H.F. and Land, R. (2003) 'Threshold concepts and troublesome knowledge (1) linkages to ways of thinking and practising', in Rust, C. (ed.) Improving student learning - ten years on. Oxford: Oxford Centre for Staff and Learning Development.

Meyer, J.H.F. and Land, R. (eds.) (2006) Overcoming barriers to student understanding: threshold concepts and troublesome knowledge. Abingdon: Routledge.

Orsini-Jones, M. (2006) 'Identifying troublesome concepts and helping undergraduates with crossing grammar thresholds via assessed collaborative group work', Threshold Concepts within the Disciplines Symposium. Glasgow. 
Osmond, J., Turner, A. and Land, R. (2006) 'Threshold concepts and spatial awareness in transport and product design', Threshold Concepts within the Disciplines Symposium. Glasgow.

Perkins, D. (2006) 'The underlying game: troublesome knowledge and threshold conceptions', in Meyer, J.H.F. and Land, R. (eds.) Overcoming barriers to student understanding: threshold concepts and troublesome knowledge. Abingdon: Routledge.

Reimann, N. and Jackson, I. (2006) 'Threshold concepts in economics: a case study', in Meyer, J.H.F and Land, R. (eds.) Overcoming barriers to student understanding: threshold concepts and troublesome knowledge. Abingdon: Routledge.

\section{Author details}

Glynis Cousin is director of the Institute for Learning Enhancement at the University of Wolverhampton. Her professional background ranges from school, community, adult and higher education. Her research and publications are in the fields of diversity, internationalisation and threshold concept inquiry. 